\title{
High Wind Power Penetration Large-Scale Hybrid Renewable Energy System Design for Remote Off-Grid Application
}

\author{
Samuel L. Tesema ${ }^{1 *}$, Getachew Bekele ${ }^{2}$ \\ ${ }^{1}$ Department of Electronic and Electrical Engineering, University of Nottingham, Nottingham, United Kingdom \\ ${ }^{2}$ School of Electrical and Computer Engineering, Addis Ababa University, Addis Ababa Institute of Technology, Addis Ababa, \\ Ethiopia \\ Email: *samuel.tesema@yahoo.com
}

How to cite this paper: Tesema, S.L. and Bekele, G. (2019) High Wind Power Penetration Large-Scale Hybrid Renewable Energy System Design for Remote Off-Grid Application. Journal of Power and Energy Engineering, 7, 11-30.

https://doi.org/10.4236/jpee.2019.73002

Received: January 14, 2019

Accepted: March 25, 2019

Published: March 28, 2019

Copyright $\odot 2019$ by author(s) and Scientific Research Publishing Inc. This work is licensed under the Creative Commons Attribution International License (CC BY 4.0).

http://creativecommons.org/licenses/by/4.0/

\section{(c) (i) Open Access}

\begin{abstract}
This study looks into the resource assessment, technology economics and modeling of different energy alternatives and proposes a rechargeable battery storage-based large-scale wind/photovoltaic hybrid power system to meet an average electrical load demand of 2.4 MW and peak load of 2.9 MW for a remote rural district in Ethiopia called Geladin. The district is $682 \mathrm{~km}$ away from nearby grid. The site enjoys high solar and wind resources that can be harnessed for electric power generation to electrify the community. HOMER simulation software is used for optimal sizing and techno-economic analysis. The diesel generator is used as back up to fill the gaps in case both resources are out. Average monthly solar irradiation data of $6.2 \mathrm{kWh} / \mathrm{m}^{2}$ is determined from measured sunshine duration data by implementing a suitable specific model for the site. NASA satellite based estimated wind speed data of 10 years average at hub height of $50 \mathrm{~m}$ for the site in question is extracted from the SWERA (Solar and Wind Energy Resource Assessment) database (with annual average of $6.1 \mathrm{~m} / \mathrm{s}$ ) and its weigh-bull distribution parameter, $\mathrm{k}$ of 1.98 is estimated which indicates a fair wind speed distribution of the site to generate electric power using wind turbine. The proposed optimal system results electricity generation indicates that $92 \%$ from wind turbine, $3 \%$ from photovoltaic, 5\% from diesel generator and managed to obtain a much lower cost of energy $(\mathrm{COE}=0.11 \mathrm{USD} / \mathrm{kWh})$ than other alternatives investigated in this study such as grid extension and diesel generator.
\end{abstract}

\section{Keywords}

Hybrid System, Renewable, Wind Energy, Photovoltaic, Optimization 


\section{Introduction}

Ethiopia is a landlocked Sub Saharan country located in the eastern horn of Africa with a total surface area of 1.1 million square kilometers and a population of around 90 million in 2014 with annual population growth rate of $2.89 \%$ [1] [2] [3]. Although Ethiopia has crafted ambitious energy targets by its five-year (2010-2015) economic strategy - the Growth and Transformation Plan (GTP), access challenges remain. Over half of the population is located geographically close to the electricity grid, but actual interconnection rates are just $23 \%$. Per capita domestic electricity consumption is less than $100 \mathrm{kWh}$ per year with a residential tariff rate of US $\$ 0.03$ [2] [3]. As traditional biomass is the main energy source in Ethiopia mainly for household cooking and accounts for $89 \%$ of total domestic energy consumption.

The installed electricity generating capacity in Ethiopia is about $2300 \mathrm{MW}$ ( $86 \%$ hydro, $6 \%$ fossil fuel and $8 \%$ geo-thermal and wind) [2] [3]. The country is completely reliant on imports to meet its petroleum requirements [1]. Energy is a key component of any poverty eradication and sustainable development strategy. Better access to sustainable energy service for rural people in Ethiopia is pre-requisite for sufficient supply of lighting, communication systems, and the development of income generating activities as well as improvement of the public health status. Today, it is widely accepted that Renewable Energy System (RES) has a large potential to contribute to the strengthening and development of national sustainable energy infrastructures in many countries in the world by securing better energy independence through the mobilization of domestic renewable energy resources especially in rural areas [4] [5]. The benefit of electrifying rural areas in Ethiopia is enormous. Electricity access improves health by facilitating longer working hours for health stations, and a strengthened cold chain for vaccines. Education level improves as electric lighting extends study hours. Small businesses, which rely heavily on family labor, can increase their production hours once electricity becomes available.

With almost $85 \%$ of the Ethiopians living in rural areas, there is a significant bias between the power supply of urban and rural population: only $2 \%$ of the rural but $86 \%$ of the urban residents have access to electricity [1] [8]. The Ethiopian government attempted to reach rural areas through grid extension and diesel generator by subsidizing rural electrification programs. One of such big programs was Universal Electricity Access Program (UEAP) in 2005 with the initial objective of electrifying 50 percent of rural towns within five years. In most cases, these projects have failed to reach the targeted customers. Percentage of population receiving electricity in rural area is less than $15 \%$ of the total population [9]. It is thus evident that alternative approaches to rural electrification schemes have to be devised [6] [7]. Hybrid power system can address limitations in terms of fuel flexibility, efficiency, reliability, emissions and economics of each power source used as a standalone system [5] [10] [11].

Geladin is a remote rural town in far eastern Ethiopia (Figure 1(a)), located in the Warder zone of the Somali region [6]. This town has a latitude and longitude 


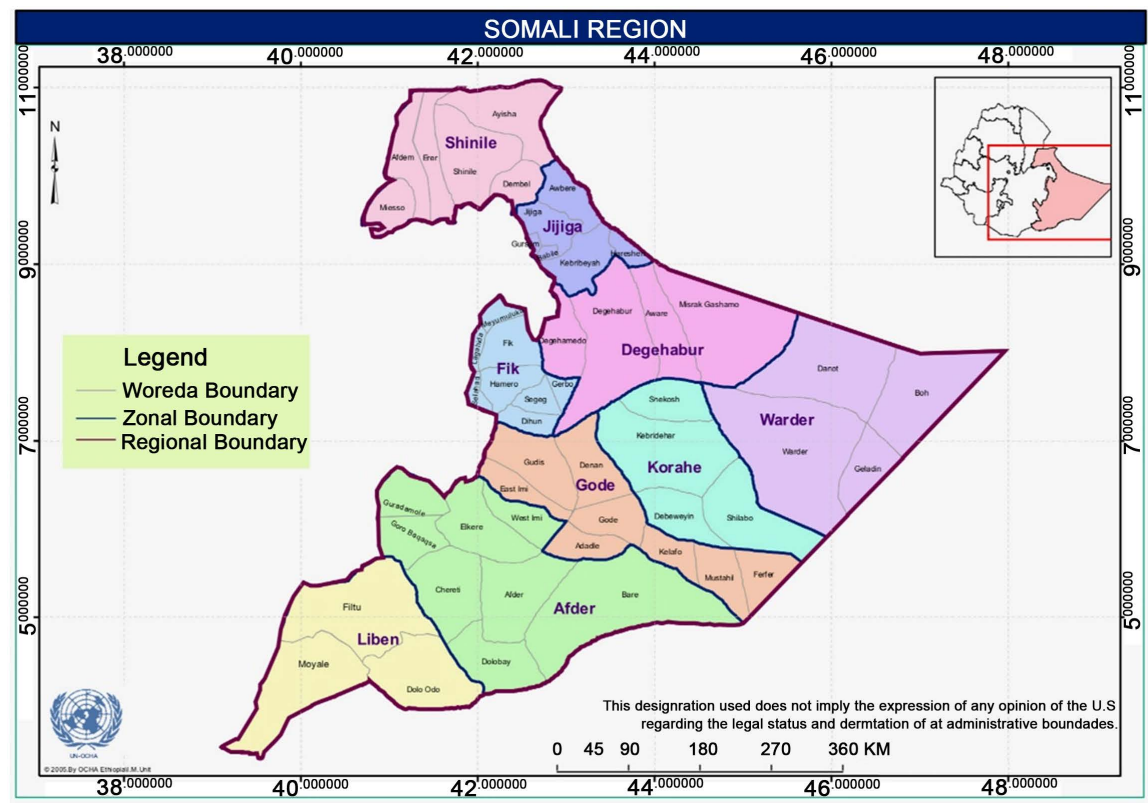

(a)

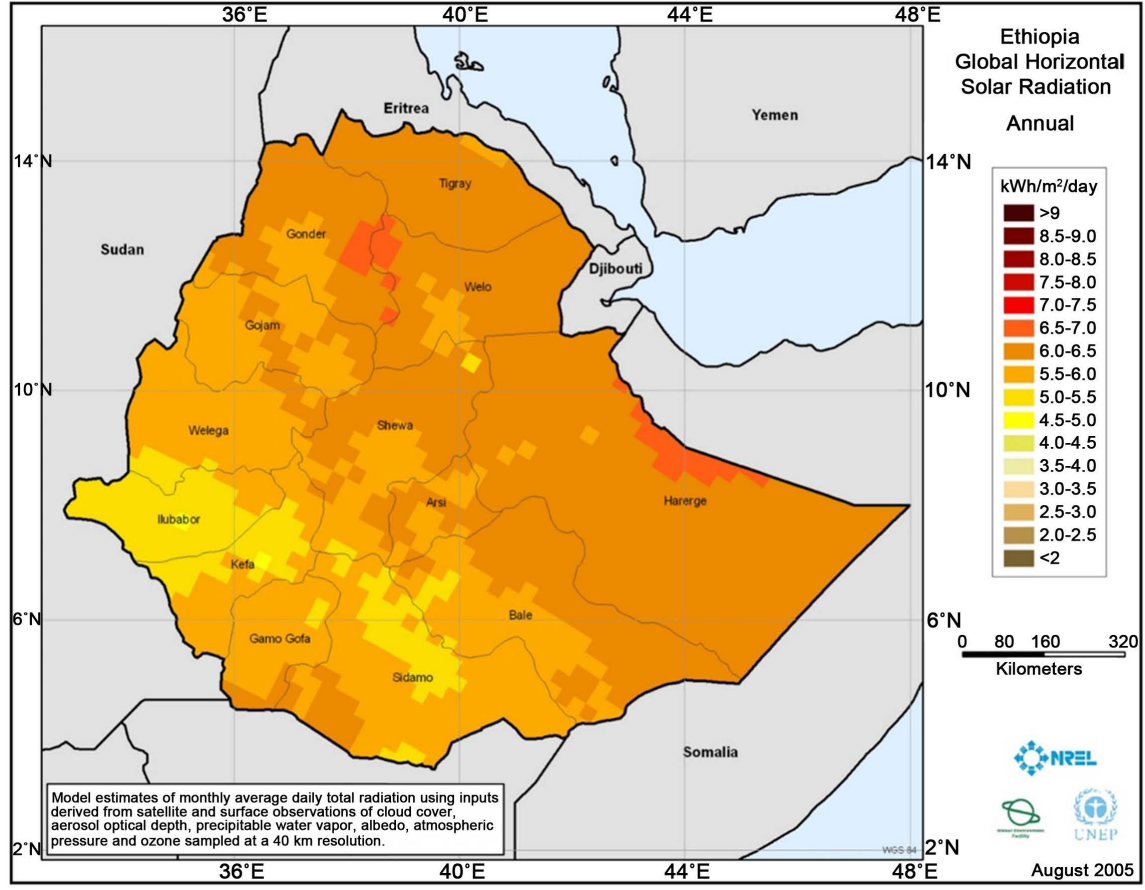

(b)

Figure 1. Shows (a) the Somali Region of Ethiopia and Geladin District; (b) Shows the global solar radiation map of Ethiopia [6] [7].

of $06^{\circ} 57^{\prime} \mathrm{N} 46^{\circ} 25^{\prime} \mathrm{E}$ with an elevation between 427 and 530 meters above sea level. Based on figures from the Central Statistical Agency in 2005, this district has an estimated total population of 10,795 with $3 \%$ of population growth rate [12]. As shown in Figure 1(b), the region has average monthly solar radiation of 6.2 $\mathrm{kWh}$ /day with average monthly wind speed of $6.1 \mathrm{~m} / \mathrm{s}$ [7]. Geladin district is found $682 \mathrm{Km}$ away from the national electricity grid and the district is electri- 
fied with a diesel generator. The diesel generator only runs 3 to 4 hours a day during night time mainly to support lighting load due to shortage of fuel and lack of maintenance [13] [14]. This district is not included in EEPCo's 10 years master plan of electrification with national grid.

Ethiopia is well endowed with renewable energy resources (45 GW hydro power, average solar energy radiation $5.5 \mathrm{kWh} / \mathrm{m}^{2} /$ day, average wind speed 5 $7.5 \mathrm{~m} / \mathrm{s}$ and $10 \mathrm{GW}$ of geothermal power) [3]. In this study one of the remote districts in the Somali region of Ethiopia called Geladin is analyzed for its renewable energy resource and electrification potential using hybrid renewable energy systems (RES) with other alternative electrification options.

As part of Ethiopia's ambitious plan to create $100 \%$ carbon free energy source in 2025, replacing the stand-alone conventional diesel generators with renewable energy power supplies has paramount importance to meet the target. Therefore, this study proposes wind and solar based hybrid mini-grid energy system to electrify the district by performing techno-economic comparative analysis among hybrid renewable energy system, grid extension and stand-alone diesel generator system.

\section{Methodology}

The methodologies used in this study are field survey and assessment of secondary data sources for the site in question. Analytical method of estimating solar radiation from sunshine hour is used to calculate the average monthly solar radiation from sun shine duration data. This method is first proposed by Angstrom and called Angstrom method of estimating solar radiation of a certain location from measured sunshine duration data [15] [16].

The National Meteorology Agency of Ethiopia (NMA) has only sunshine duration data from nearby station of Kebredahar. NASA-measured wind speed data has been taken from SWERA satellite data base. The electrical load of the site has been estimated through field survey of the appliances used by residents. However, in this study, energy efficient CFL lamps and other energy efficient electric appliances are used. For sizing and optimization of the hybrid energy system, a simulation software called HOMER is used. To control power balance of the system, thermal load and back up diesel generator are used. If the supply is larger than demand at a particular time, the excess electricity can be fed to thermal loads or other load such as pumped storage to use during peak load time; and if the demand is greater than the supply, diesel generator starts automatically. In order to avoid frequent start and stop of diesel generator, battery bank is included to supply small peak loads.

\subsection{Solar Radiation Estimation from Sunshine Duration Data}

In this study the empirical formula proposed by Mulugeta Y. and Drake F. [16] is used. These authors used Angstrom equation and found the corresponding coefficients which can be applied to different sites in Ethiopia. The proposed linear correlation equation and the original Angstrom equation are shown below. 


$$
H=H_{o}\left[a+\frac{S}{S_{O}} b\right]
$$

where:

$H$ : monthly average daily radiation on horizontal surface $\left(\mathrm{MJ} / \mathrm{m}^{2}\right) ; H_{o}$ : is monthly average daily extraterrestrial radiation on a horizontal surface $\left(\mathrm{MJ} / \mathrm{m}^{2}\right)$; $S_{O}$ : the maximum possible daily hours of bright sun-shine; $S$ : monthly average daily number of hours of bright sunshine. $a$ and $b$ are regression coefficients which can be obtained using the following equations for $M$ number of data points.

$$
a=\frac{\sum \frac{H}{H_{O}} \sum\left(\frac{S}{S_{O}}\right)^{2}-\sum \frac{S}{S_{O}} \sum \frac{S}{S_{O}} \frac{H}{H_{O}}}{M \sum\left(\frac{S}{S_{O}}\right)^{2}-\left(\sum \frac{S}{S_{O}}\right)^{2}} ; b=\frac{M \sum \frac{S}{S_{O}} \frac{H}{H_{O}}-\sum \frac{S}{S_{O}} \sum \frac{H}{H_{O}}}{M \sum\left(\frac{S}{S_{O}}\right)^{2}-\left(\sum \frac{S}{S_{O}}\right)^{2}}
$$

The values of the monthly average daily extraterrestrial radiation $\left(H_{o}\right)$ are calculated for days giving average of each month as:

$$
\begin{aligned}
H_{o}= & \left(\frac{24 \times 3600}{\pi}\right) G_{s c}\left[\left(1+0.033 \cos \left(\frac{360 n_{d}}{365}\right)\right)\right. \\
& \left.\times\left(\cos \varnothing \cos \delta \sin \omega_{s}+\frac{2 \pi}{360} \omega_{s} \sin \varnothing \sin \delta\right)\right]
\end{aligned}
$$

where:

$$
\begin{aligned}
& n_{d} \text { : day number starting from } 1^{\text {st }} \mathrm{January} \text { as } 1 ; \\
& G_{s c} \text { (the solar constant) }=1367 \mathrm{~W} / \mathrm{m}^{2} \text {; } \\
& \varnothing \text { : Latitude of the location; } \\
& \delta \text { : Declination angle }\left(^{\circ}\right) ; \\
& \omega_{s}=\text { Sunset hour angle }\left(^{\circ}\right) . \\
& \qquad \delta=23.45 \sin \left(360 \frac{284+n_{d}}{365}\right) \\
& \qquad \omega_{s} \cos ^{-1}(-\tan \varnothing \tan \delta)
\end{aligned}
$$

The maximum possible daily hours of bright sunshine can be calculated by using the following equation:

$$
S_{O}=\frac{2}{15} \omega_{s}
$$

The proposed equation by Mulugeta Y. and Drake F. [16] after calculating the coefficients a and b:

$$
\frac{H}{H_{O}}=\left[0.33+0.43 \frac{S}{S_{O}}\right]
$$

Therefore, using the above equations, the parameters listed below in Table 1 including $\mathrm{Ho}$ and $\mathrm{H}$ are estimated.

The annual monthly average solar irradiation value calculated using the above model is compared with the corresponding monthly average daily radiation data obtained from NASA and NREL and as a result the model by Mulugeta Y. and 
Table 1. Calculated monthly solar radiation (Latitude $=6.67)$ and Solar radiation data from NASA and SWERA (Ho and $\mathrm{H}$ in $\mathrm{kwh} / \mathrm{m}^{2} / \mathrm{d}$ ) [7].

\begin{tabular}{cccccccccc}
\hline $\begin{array}{c}\text { Mid of } \\
\text { Month }\end{array}$ & $\mathrm{n}_{\mathrm{d}}$ & $\delta$ & $\omega_{\mathrm{S}}$ & $\mathrm{N}$ & $\mathrm{n}$ & $\mathrm{Ho}$ & $\begin{array}{c}\text { Calculated } \\
\text { NMA, } \mathrm{H}\end{array}$ & $\mathrm{H}$ H & \multicolumn{2}{c}{ SWERA } \\
\hline Jan-15 & 15 & -21.27 & 87.39 & 11.65 & 9.78 & 9.27 & 6.80 & 5.91 & 6.362 \\
Feb-14 & 45 & -13.62 & 88.38 & 11.78 & 9.85 & 9.86 & 6.98 & 6.50 & 6.831 \\
Mar-15 & 74 & -2.82 & 89.67 & 11.96 & 9.56 & 10.37 & 6.75 & 6.57 & 6.882 \\
Apr-15 & 105 & 9.42 & 91.11 & 12.15 & 8.91 & 10.46 & 5.95 & 6.10 & 6.477 \\
May-15 & 135 & 18.79 & 92.28 & 12.30 & 7.23 & 10.21 & 5.65 & 5.94 & 6.239 \\
Jun-15 & 166 & 23.31 & 92.89 & 12.39 & 6.83 & 9.97 & 5.36 & 5.56 & 6.234 \\
Jul-15 & 196 & 21.52 & 92.64 & 12.35 & 5.87 & 10.03 & 5.85 & 5.47 & 6.022 \\
Aug-15 & 227 & 13.78 & 91.64 & 12.22 & 6.79 & 10.28 & 6.50 & 6.00 & 6.491 \\
Sep-15 & 258 & 2.22 & 90.26 & 12.04 & 8.35 & 10.35 & 6.14 & 6.28 & 6.769 \\
Oct-15 & 288 & -9.60 & 88.87 & 11.85 & 7.83 & 9.99 & 6.06 & 5.47 & 6.157 \\
Nov-15 & 319 & -19.15 & 87.67 & 11.69 & 8.57 & 9.39 & 6.20 & 5.56 & 6.281 \\
Dec-15 & 349 & -23.34 & 87.11 & 11.61 & 9.56 & 9.06 & 6.22 & 5.58 & 6.141 \\
Average & & & & & & & 6.205 & 5.90 & 6.4072 \\
\hline
\end{tabular}

Drake F. has shown estimation that approaches almost similar seasonal trends to the data from NASA and NREL with very small Root Mean Square Error (RMSE) (Figure 2).

\subsection{Wind Energy}

Many literatures suggest wind resource availability [14] [17] [18] in the district of Geladin which can conveniently be harnessed for electricity generation despite its seasonal fluctuation as shown in Figure 3 below. Eight years wind speed and direction data are taken from nearby station measured at anemometer height of 2 meters. But the purpose of measurement was for weather forecasting in local aircraft flight control [14] and therefore not a reliable one to consider it for design. In this study a wind speed data measured by NASA which is taken from SWERA database [7] is considered for optimization and modeling of the hybrid system.

The monthly average annual wind speed of the site is $6.1 \mathrm{~m} / \mathrm{s}$. Its best-fit weigh bull parameter and data map (DMap) are generated using HOMER software as shown in the Figure 3(a) and Figure 3(b). A k value (weigh bull shape factor) of 1.98 is obtained which indicates a reasonable amount of wind speed distribution on the site. Figure 3(a) shows a DMap of the diurnal pattern strength of the site's wind speed, which is a measure of how strongly the wind speed tends to depend on the time of day. Since wind is typically affected by solar radiation, most locations show some diurnal (or daily) pattern in wind speed [19].

The height-speed correction to the wind speed at hub height of $78 \mathrm{~m}$ is calculated using the logarithmic profile (log law) which assumes that the wind speed is proportional to the logarithm of the height above ground. 


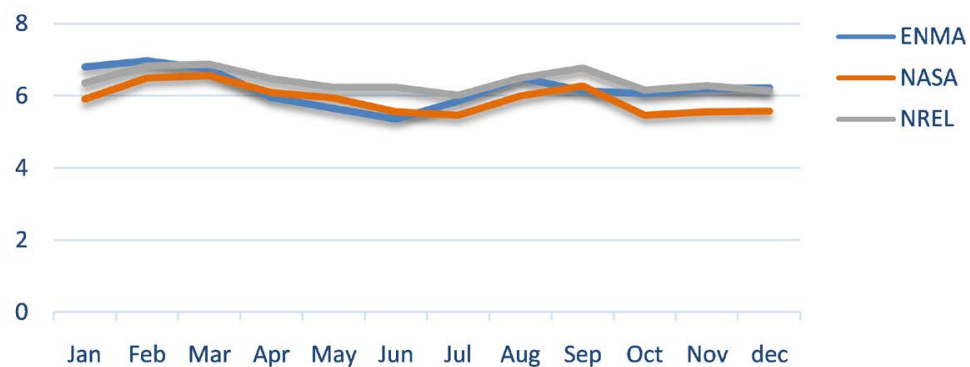

Figure 2. Comparison of the estimated NMA monthly average daily solar radiation with NASA and NREL [7].

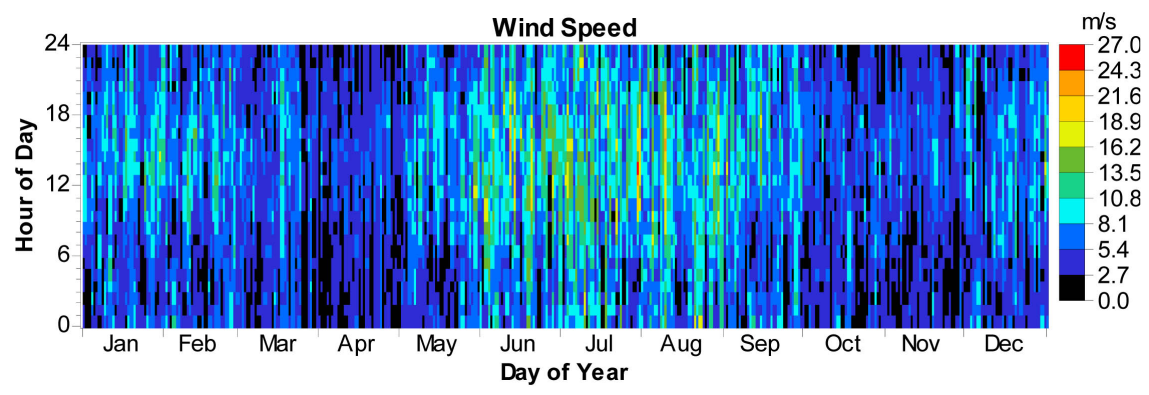

(a)

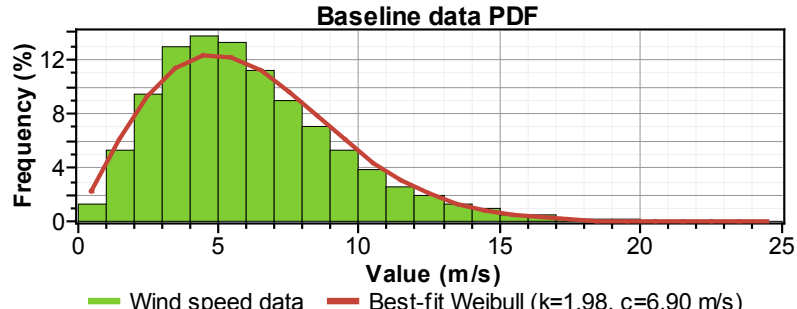

(b)

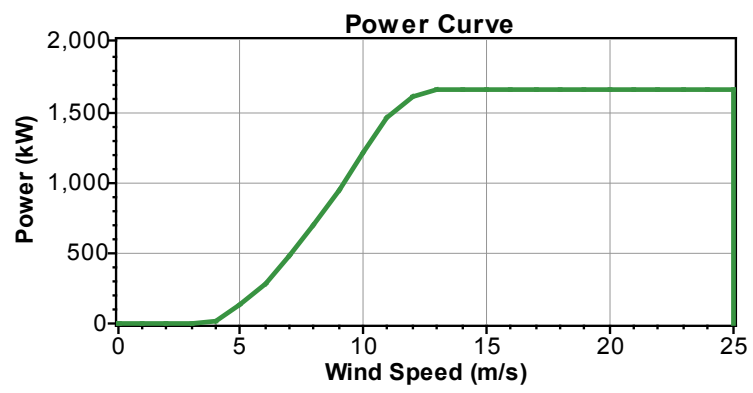

(c)

Figure 3. Shows (a) the DMap indicating one year of hourly data which allows daily and seasonal patterns for wind speed of the site; (b) Probability Density Function (PDF) of the wind speed distribution; (c) Power curve for Vestas V82 model wind turbine.

$$
\frac{v\left(z_{\text {hub }}\right)}{v\left(z_{\text {anem }}\right)}=\frac{\ln \left(z_{\text {hub }} / z_{o}\right)}{\ln \left(z_{\text {anem }} / z_{o}\right)}
$$

where:

$Z_{h u b}=$ the hub height of the wind turbine $[\mathrm{m}] ; Z_{\text {anem }}=$ the anemometer height $[\mathrm{m}]$ 
$Z_{0}=$ the surface roughness length $[\mathrm{m}] ; V\left(z_{h u b}\right)=$ wind speed at the hub height of the wind turbine $[\mathrm{m} / \mathrm{s}]$;

$v\left(z_{\text {anem }}\right)=$ wind speed at anemometer height $[\mathrm{m} / \mathrm{s}] ; \ln (\ldots)=$ the natural logarithm.

\subsection{Electrical Load Estimation}

As Geladin district has already been electrified with diesel generator, estimation of the load is straight forward. However, in this study energy efficient loads are selected, and future load growth is also considered. As shown in Figure 4, the total primary load (load that needs continuous supply) and deferrable load (load with some storage capability) for the site is $30 \mathrm{MWh} /$ day with peak load of 2.7 $\mathrm{MW}$ and $21 \mathrm{MWh} /$ day with peak load of $2.3 \mathrm{MW}$ respectively. It is clearly seen from the load DMap in Figure 4 (a) that load demand is higher (peak load) in the morning from around $10 \mathrm{am}$ to $1 \mathrm{pm}$ and even higher in the evening from $6 \mathrm{pm}$ to $9 \mathrm{pm}$. The Deferrable load in Figure 4(a) shows monthly variation especially during high windy seasons since the load is electric motor for water pump to serve community water supplies for drinking and irrigation. This load decreases in winter due to rain water availability for agriculture. The system control serves deferrable load whenever it senses spare energy after meeting primary load demand. In case of low storage tank level, the system control prioritizes meeting deferrable load than battery charging.

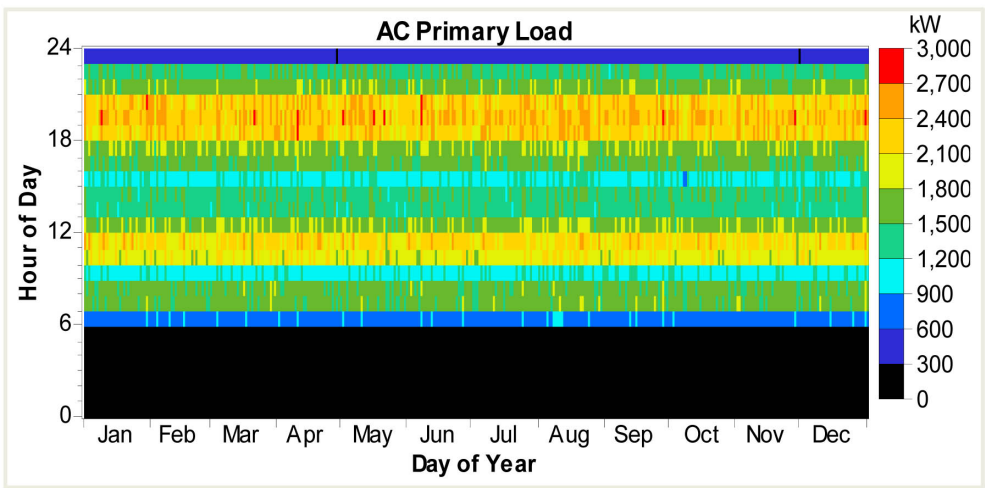

(a)

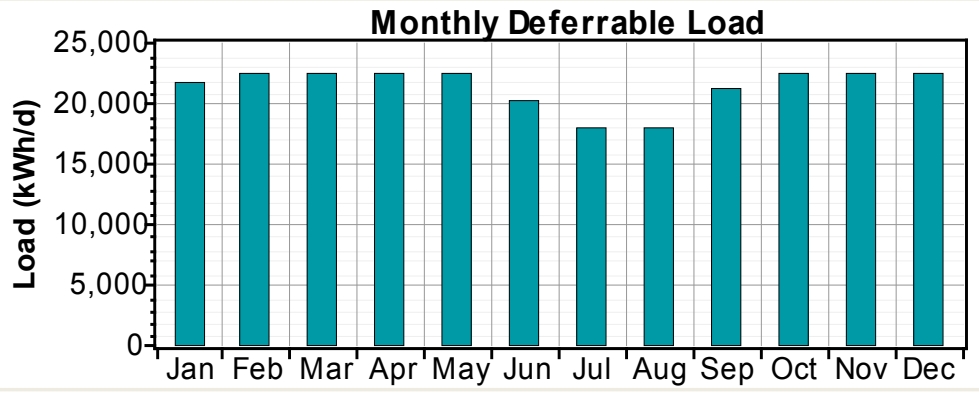

(b)

Figure 4. Shows (a) the hourly DMap of primary load data within a year; (b) monthly average deferrable electrical load demand. 


\subsection{Grid Extension Option}

Grid Extensions connects a load to the local utility grid. If available, grid power is typically the most cost-effective power supply although the cost of extending lines to rural facilities can be prohibitively expensive. Grid extension varies in cost depending on the utility, the terrain, the distance to be covered, and the size of the load to be served. If the local grid is fairly reliable and within a few miles, obtaining an estimate for the capital cost of grid extension and the recurring cost of electricity will give points of comparison when considering other options.

In this work a total cost analysis for grid extension option to the site is considered to see whether it is feasible compared to renewable energy system and other alternative power sources. Since the site in question is $682 \mathrm{~km}$ away from the national grid owned by Ethiopian Electric Power Corporation (EEPCo), a transmission line (including all necessary accessories) is designed and the equivalent cost is analyzed. For this purpose, a load forecasting for 25 years is estimated by taking annual electric demand growth rate of $3 \%$ [20] and a loss of $25 \%$.

To estimate the cost of grid extension per kilometer distance, the most economical transmission voltage KV rating should be determined first from the forecasted load and distance of the grid to the electrified site by using the empirical equation:

$$
V=5.5 * \sqrt{\left(\frac{L}{1.6}+10 P\right)}
$$

where $V$ is the economical three phase transmission voltage (KV); $L$ is distance of transmission line needed $(\mathrm{km}) ; P$ is load demand in MW.

The capital cost for the estimated transmission line of $132 \mathrm{KV}$ standard voltage for the remote load is $327,932.44 \mathrm{USD} / \mathrm{km}$ and the operating and maintenance cost is $2 \%$ of the capital cost per year [21] [22]. The TNPC, Capital cost and Cost of Energy (COE) is estimated for the option of modeling the transmission line using the following equations:

$$
\mathrm{COE}=\frac{C_{a n n, t o t}}{L_{a n n, t o t}}
$$

where: $C_{\text {ann,tot }}$ is total annualized cost of the grid extension (KWh/yr), $L_{a n n, t o t}$ is total annualized load served (KWh/yr).

The total annualized cost is the sum of the annualized cost of each system component. The annualized cost of a grid extension is equal to its annual operating cost plus its capital cost annualized over the project lifetime.

$$
C_{\text {ann }}=C_{\text {acap }}+C_{a O M}
$$

where $C_{a n n}=$ annualized cost, $C_{\text {acap }}=$ annualized capital cost and $C_{a O M}=$ annualized operating and maintenance cost.

$$
C_{\text {acap }}=C_{\text {cap }} * C R F\left(i, R_{\text {proj. }}\right)
$$

where $C_{c a p}$ is initial capital cost of grid extension, $C R F$ is capital recovery factor, $i$ is annual real interest rate (\%) and $R_{p r o j}$ is project life time (year). 


$$
C R F\left(i, R_{\text {proj }}\right)=\left[\frac{i(1+i)^{N}}{(1+i)^{N}-1}\right]
$$

Lastly the total net present cost (life time cost) of grid extension can easily be calculated using the equation:

$$
C_{N P C}=\frac{C_{a n n, t o t}}{C R F\left(i, R_{p r o j}\right)}
$$

A value of $i=7 \%$ and $R_{\text {proj }}=N=25$ years is taken for calculating the grid extension Annualized cost, Net present cost (NPC) and levelized cost of energy (COE).

\section{System Architecture}

Hybrid power systems are combinations of two or more energy conversion devices (e.g., electricity generators or storage devices), or two or more fuels for the same device, that when integrated, overcome limitations that may be inherent in either. Hybrid systems can produce synergistic benefits in which the "whole is greater than the sum of its parts". System efficiencies are typically higher than that of the individual technologies used separately, and higher reliability can be accomplished with energy storage. Some hybrid systems include both which can simultaneously improve the quality and availability of power. In general, well-designed hybrid systems will substantially reduce diesel fuel consumption while increasing system reliability. In addition to the diesel generator and the renewable energy generator, hybrid systems consist of a battery bank for energy storage, a control system and particular system architecture that allows optimal use of all components. The optimal generator size in this study as shown at Figure 5 consists of wind turbine, photovoltaic and diesel generator (as back up) [19]. Battery bank is included to avoid frequent startup of diesel generator. The schematic architecture of the designed system is shown below.

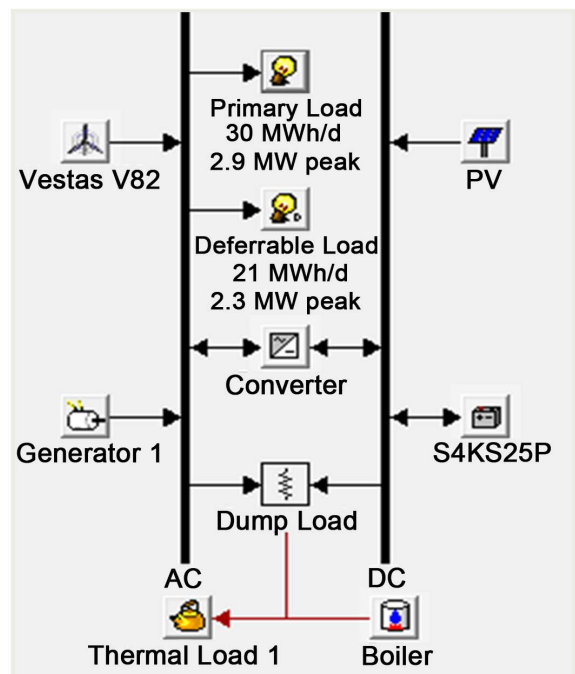

Figure 5. Hybrid energy system model generated by HOMER [19]. 
There are different architectural connections among various energy generators and auxiliary devices [23]. The architecture of connection defines whether the generators are connected to DC bus or AC bus. In the DC bus configuration, all generators connected to DC bus with some intermediate interface as needed. In Ac configuration all generators are connected to AC bus. The Advantage of $\mathrm{AC}$ configuration is the diesel generator can be directly connected to the AC bus provided its voltage and frequency is similar with that of bus voltage and frequency. It is for this reason AC configuration has higher efficiency than DC.

\section{Power Generators Sizing and Optimization}

\subsection{Simulation with HOMER}

In this study HOMER software [19] is used to size generators optimally and to perform techno-economic assessment of the designed system. HOMER performs three tasks: simulation, optimization and sensitivity analysis [19] [24]. At simulation stage, HOMER investigates the performance of a particular power system configuration for each hour of the year to determine its technical feasibility and life cycle cost. The designer can easily find the least cost system at the top of the list or scan the list for other feasible systems according to the site-specific situation. Sensitivity analysis helps see how the results vary with regard to changes in inputs, either because they are uncertain or because they represent a range of applications. HOMER repeats the optimization process for each value of the input so that one can examine the effect of changes in the value on the results. After simulating all possible system configurations, HOMER displays a list of feasible systems, sorted by life cycle cost. The life cycle cost is the optimization criterion. The output of the simulation helps answer the basic question [19] during the design process such as: Which technologies are most cost-effective? What size should components be? What happens to the project's economics if costs, load demands, or resources change? Is the renewable resource adequate?

HOMER's optimization and sensitivity analysis capability helps the designer to answer these difficult questions. The software input windows require data like capital, replacement and operating and maintenance cost of the generators; monthly solar and wind resource data (monthly renewable resource of the site); fixed cost of the system if any, the economic constraints such as real interest rates, hourly and daily energy reserve required etc. Table 2 shows the inputs applied to HOMER.

\subsection{Sensitivity Variables}

Sensitivity variables help the designer to consider uncertain matters that might affect the system's performance or feasibility in the future of project life time. Sensitivity variables chosen in this study are the price of diesel fuel and PV modules. Since the system is designed for 20 year life time, these values are the most fluctuating variables. It is likely that the price of PV module is going to decline in the future whereas that of diesel fuel fluctuates unevenly. The sensitivity values given in Table 3 below are used for simulation. 
Table 2. Component size and price inputs for simulation.

\begin{tabular}{|c|c|c|c|c|c|c|}
\hline Components & $\begin{array}{l}\text { Size } \\
(\mathrm{KW})\end{array}$ & $\begin{array}{l}\text { Capital Cost } \\
(\$)\end{array}$ & $\begin{array}{l}\text { Replacement } \\
\text { Cost }(\$)\end{array}$ & $\begin{array}{c}\mathrm{O} \& \mathrm{M} \\
\text { Cost }(\$ / \mathrm{yr})\end{array}$ & $\begin{array}{l}\text { Sizes to consider } \\
\text { (KW or Unit) }\end{array}$ & Life Time (Year) \\
\hline PV Module & 1 & 2106 & 1755 & 5 & $\begin{array}{c}(0,3.6,3.8,4,4.1,6,7,10,20 \\
25,120,200) \times 100 \mathrm{KW}\end{array}$ & 20 \\
\hline Wind $\mathrm{T}$. & 1650 & $1,262,190$ & 757,314 & 2000 & $0,7,8,9,10,11,18,19$ & 20 \\
\hline D. Gen. & $0-3300$ & $0-613,025$ & $0-490,420$ & $0-20 / \mathrm{hr}$ & $\begin{array}{l}(0,7,9,10,11,11.22,12,12.5 \\
14,14.5,23.33,37) \times 100 \mathrm{KW}\end{array}$ & $25,000 \mathrm{hrs}$ \\
\hline Battery & $1900 \mathrm{Ah}$ & 1221 & 1163 & 10 & $\begin{array}{c}(0,5,5.5,6.5,8,9,14,20,30 \\
42.5,50,60,70,80) \times 10\end{array}$ & $10,569 \mathrm{kwh}$ \\
\hline Converter & 4.4 & 2608 & 2608 & 40 & $\begin{array}{c}(0,5.5,5.5,6.1,12,13,14 \\
15,18,39,42,45) \times 100 \mathrm{KW}\end{array}$ & 15 \\
\hline
\end{tabular}

Table 3. Sensitivity variables.

\begin{tabular}{cccc}
\hline & Diesel Price $(\$ /$ liter $)$ & PV capital cost multiplier & PV replacement cost multiplier \\
\hline Base Values & 0.94 & 1 & 1 \\
& 0.6 & 1.4 & 1.4 \\
Sensitivity Values & 1.2 & 0.8 & 0.8 \\
& 1.4 & 0.6 & 0.6 \\
\hline
\end{tabular}

\section{Result and Discussion}

\subsection{Optimization Result}

The categorized result of the systems is shown in Table 4 below in which all system architectures are included and is listed in the increasing order of TNPC. The selected optimal system which fulfills all the imposed constraints is a rechargeable battery based Wind/PV/D. Generator hybrid energy system with levelized Cost of Energy (LCOE) of $0.11 \mathrm{USD} / \mathrm{kWh}$. The optimal system has least unmet load fraction, annual fuel consumption and $\mathrm{CO}_{2}$ emission compared to other feasible systems. As indicated in Table 5, the percentage contribution of each optimal sizing/rating of system components and their percentage contribution to the total electricity production plus its level of greenhouse gas reduction is given. There for a hybrid system with 10 * V82 type Vestas wind turbine (1.65 MW), $410 \mathrm{KW}$ PV array, $1122 \mathrm{KW}$ Genset, $650 * 1900$ Ah battery bank and $610 \mathrm{KW}$ converter ratings are optimally sized. Which system to choose from Table 4 is based on the required attribute such as less cost or more renewable fraction etc. Very high green energy penetration option can still be chosen for instance (99\%) if cost is not an issue (system Rank 6 of Table 4) with no emission yet costs almost twice the proposed system at Rank 1.

One can easily notice from the simulation result depicted below at Figure 6 and Figure 7 that there is high wind speed from June to September which 
Table 4. Categorized optimization result for Geladin district.

\begin{tabular}{|c|c|c|c|c|c|c|c|c|c|}
\hline Rank & PV (kW) & $\begin{array}{l}\text { Wind T. } \\
\text { (V82) }\end{array}$ & $\begin{array}{c}\text { D.GEN } \\
(\mathrm{kW})\end{array}$ & $\begin{array}{c}\text { Battery } \\
\text { (S4KS25P) }\end{array}$ & $\begin{array}{c}\text { Converter } \\
(\mathrm{kW})\end{array}$ & $\begin{array}{c}\text { Disp. } \\
\text { strategy }\end{array}$ & Total NPC & $\begin{array}{c}\mathrm{COE} \\
(\$ / \mathrm{kWh})\end{array}$ & $\begin{array}{c}\text { Renewable } \\
\text { fraction }\end{array}$ \\
\hline 1 & 410 & 10 & 1200 & 650 & 610 & LF & $24,949,272$ & 0.11 & 0.93 \\
\hline 2 & 0 & 9 & 1450 & 550 & 560 & LF & $24,976,992$ & 0.11 & 0.91 \\
\hline 3 & 0 & 10 & 1400 & 0 & 0 & LF & $25,833,890$ & 0.11 & 0.91 \\
\hline 4 & 700 & 10 & 1250 & 0 & 550 & LF & $26,228,008$ & 0.12 & 0.92 \\
\hline 5 & 2500 & 10 & 0 & 4250 & 1800 & $\mathrm{CC}$ & $30,033,872$ & 0.13 & 0.98 \\
\hline 6 & 0 & 18 & 0 & 7000 & 1800 & $\mathrm{CC}$ & $40,519,424$ & 0.18 & 0.99 \\
\hline 7 & 12,000 & 0 & 1400 & 4250 & 4500 & LF & $51,859,416$ & 0.24 & 0.83 \\
\hline 8 & 12,000 & 0 & 2300 & 0 & 4500 & LF & $55,988,660$ & 0.26 & 0.74 \\
\hline 9 & 20,000 & 0 & 0 & 7000 & 3900 & $\mathrm{CC}$ & $63,658,884$ & 0.30 & 0.97 \\
\hline 10 & 0 & 0 & 3760 & 1400 & 550 & LF & $69,009,848$ & 0.33 & 0 \\
\hline 11 & 0 & 0 & 3760 & 0 & 0 & LF & $69,342,016$ & 0.33 & 0 \\
\hline
\end{tabular}

Table 5. Detailed report of the proposed battery based optimal RES with wind/pv/diesel generator.

\begin{tabular}{|c|c|c|c|c|c|c|c|c|}
\hline \multicolumn{2}{|c|}{ System Architecture } & \multicolumn{2}{|c|}{ Electric Production } & \multicolumn{3}{|c|}{ Electric Consumption \& others } & \multicolumn{2}{|c|}{ Greenhouse Gases } \\
\hline Components & Size & $\mathrm{KWh} / \mathrm{yr}$ & $\%$ & & $\mathrm{KWh} / \mathrm{yr}$ & $\%$ & Pollutant & $\mathrm{kg} / \mathrm{yr}$ \\
\hline $\mathrm{PV}(\mathrm{KW})$ & 700 & 906,452 & 3 & AC primary Load & $10,683,159$ & 58.7 & Carbon dioxide & $1,619,880$ \\
\hline Wind T. (Unit) & 10 & $28,756,407$ & 92 & Deferrable Load & $7,519,853$ & 41.3 & Carbon monoxide & 3587 \\
\hline Diesel Gen. (KW) & 1122 & $1,594,105$ & 5 & Excess Electricity & 13,059160 & 41.8 & $\begin{array}{c}\text { Unburned } \\
\text { hydrocarbons }\end{array}$ & 397 \\
\hline Battery (Unit) & 650 & \multicolumn{2}{|c|}{ Cost Summary } & Unmet Load & 482,691 & 2.6 & Particulate matter & 270 \\
\hline Inverter $(\mathrm{Kw})$ & 610 & TNPC (\$) & $25,186,892$ & Capacity Shortage & 781,923 & 4.2 & Sulfur dioxide & 3259 \\
\hline Rectifier $(\mathrm{Kw})$ & 610 & LCOE & $\$ 0.11 / \mathrm{Kwh}$ & Thermal Load & & & Nitrogen oxide & 32,008 \\
\hline Disp. Strategy & LF & Oper. Cost & $\$ 820,919 / \mathrm{yr}$ & & & & & \\
\hline
\end{tabular}

resulted in contributing almost to all electricity production. The Dmap for high excess energy, battery bank state of charge, high wind turbine generation, very less usage of diesel fuel are all witnesses for high penetration of wind energy in the system in general and in windy seasons in particular. Note the system behavior in Figure 7 for battery state of charge in windy months is well above $90 \%$ thus no genset operation command is executed by the system control since fuel is more costly. Effective use or storage of these seasonal excess energy could results in increasing system efficiency and stability. 


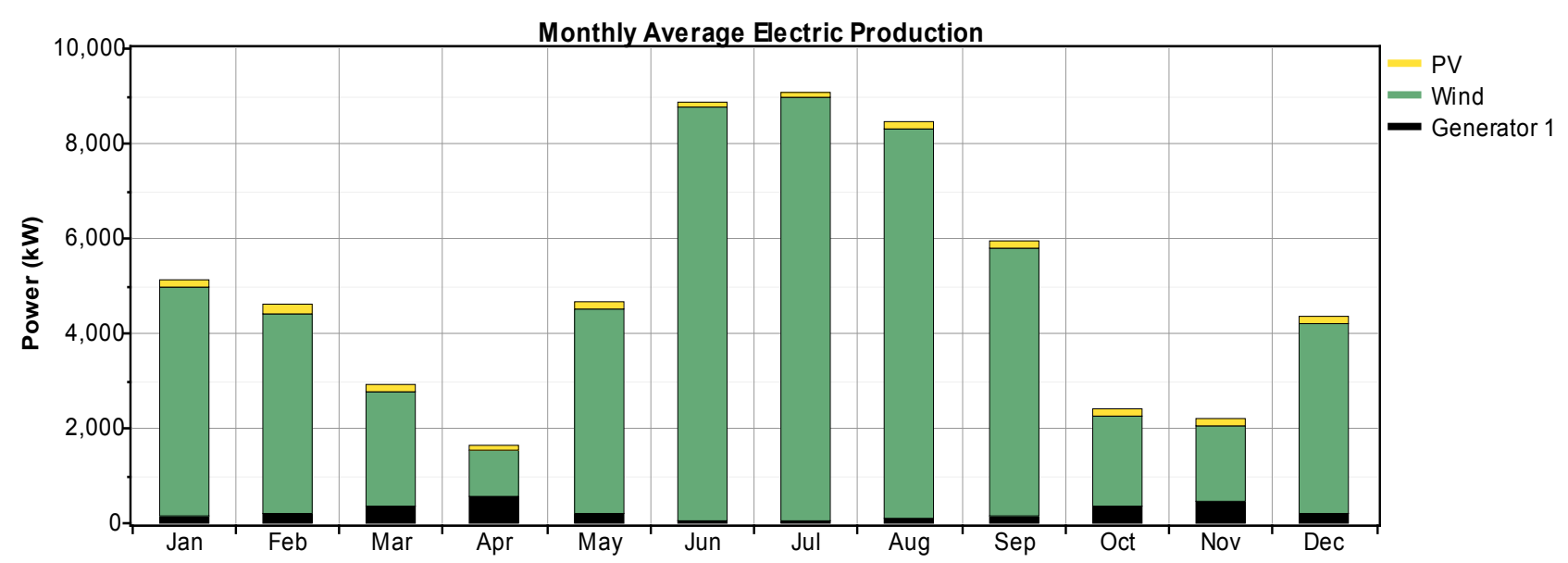

(a)

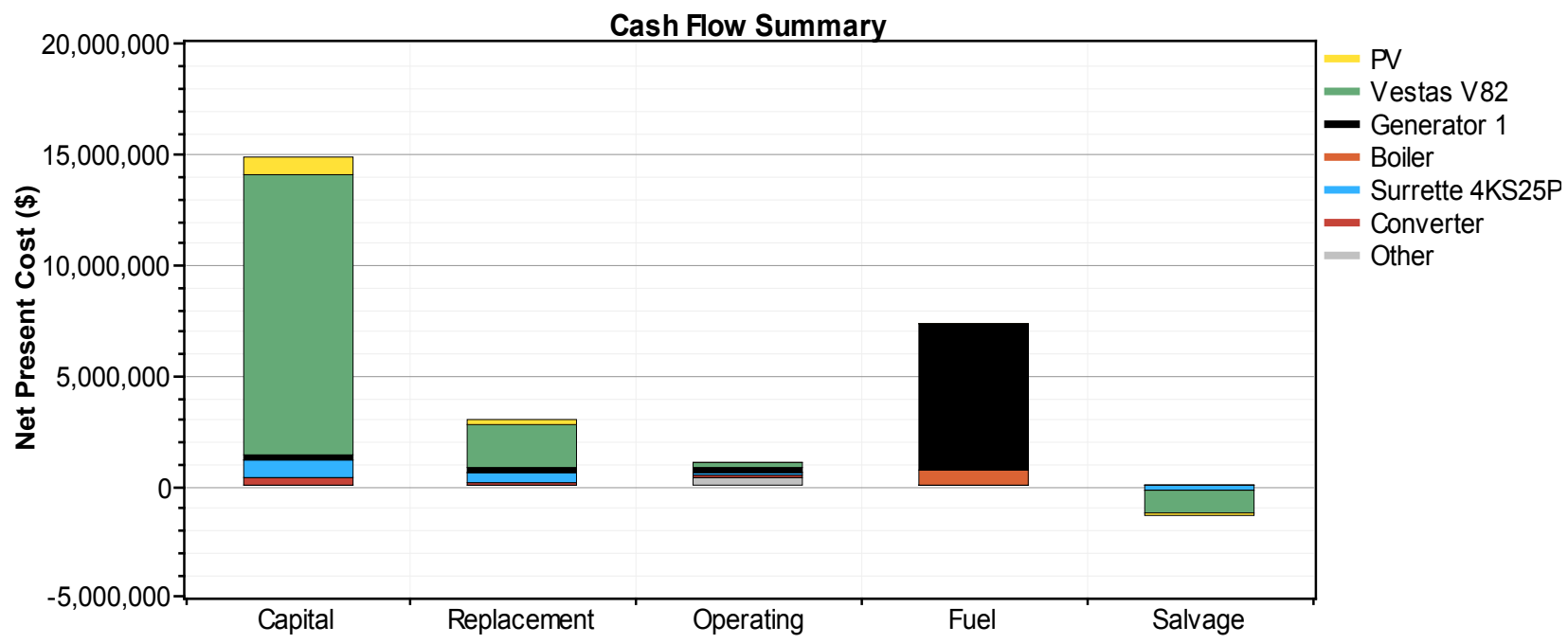

(b)

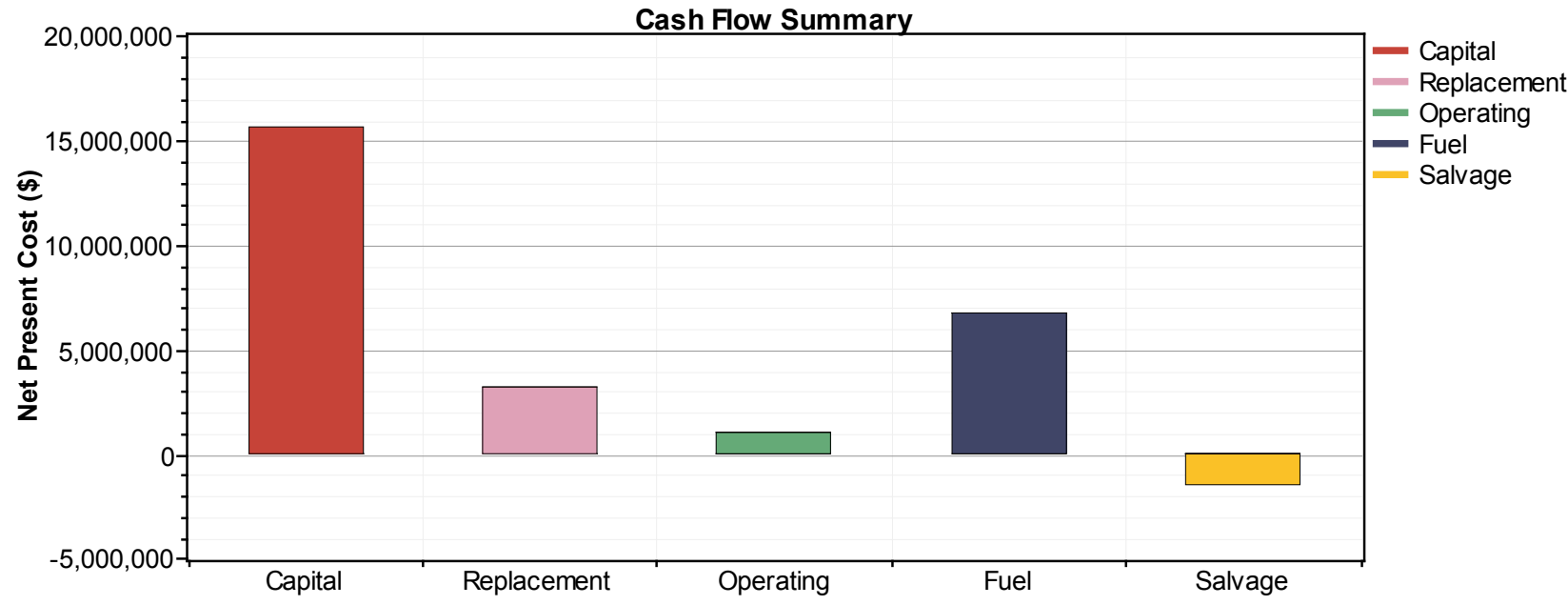

(c)

Figure 6. Shows simulation results (a) Amount of monthly average electric power production from each generator types; (b) cash flow summary (life time cost or NPC) expenditure categorized by components type in the system and (c) cash flow summary expenditure categorized by cost type. 

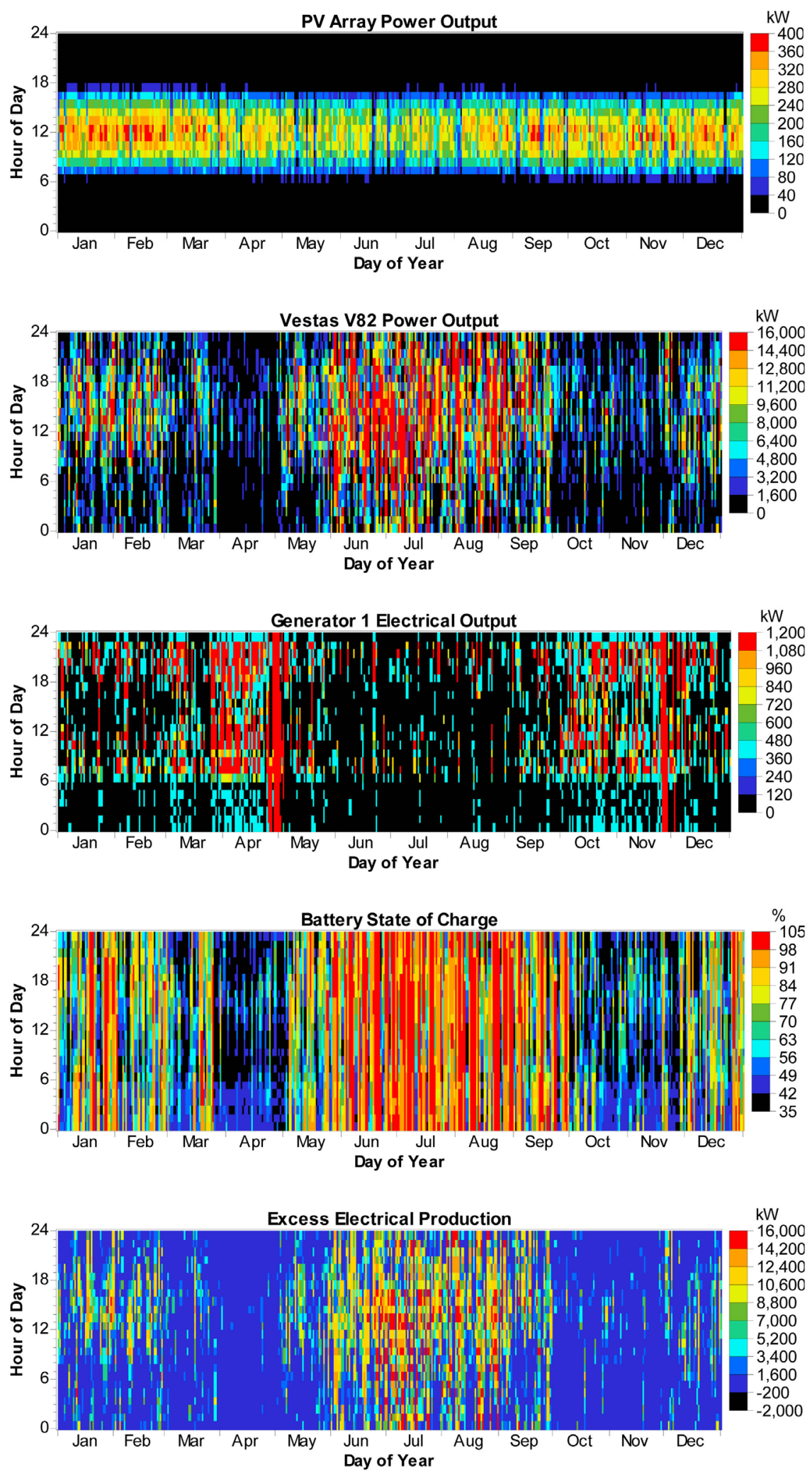

Figure 7. Shows the simulation result Dmap for electric production from different components (PV array, Wind turbine, Diesel generator, battery state of charge and excess power generation within a year) of the system (The Dmap shows the energy production for each hour of the day for every day in a year). 


\subsection{Sensitivity Result}

Sensitivity analysis was carried out for price of PV module and diesel fuel to make sure the system is still optimal under these circumstances or worst case scenarios. Accordingly, the result shows from Figure 8(a), as the PV module price multiplier goes down from 0.7 (cheaper than current market by $30 \%$ ), the hybrid system combination of Wind/PV/Generator/Battery becomes more cost effective and is no longer sensitive to the price of diesel fuel, but in case of higher future prices tendency for both fuel and PV, though the PV case is unlikely, the system prefers and more depends on wind power for its energy production as shown in Figure 8(b). A logical decision to select a hybrid system which is economical, efficient, less pollutant $\left(\mathrm{CO}_{2}\right.$ emission $)$ and reliable can easily be made

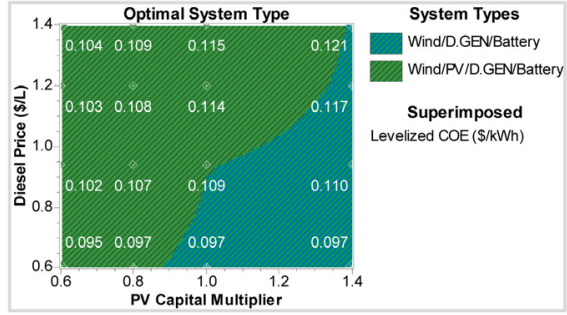

(a)

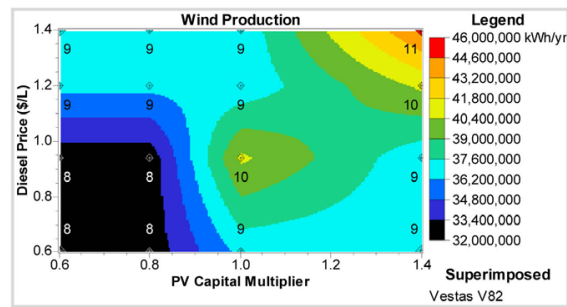

(b)

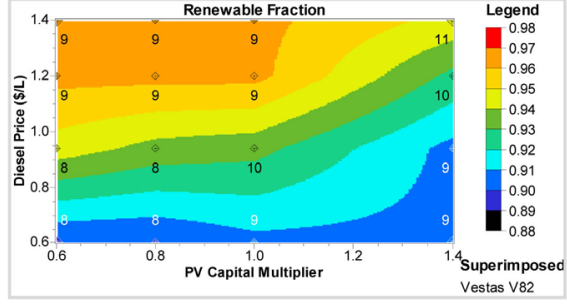

(c)

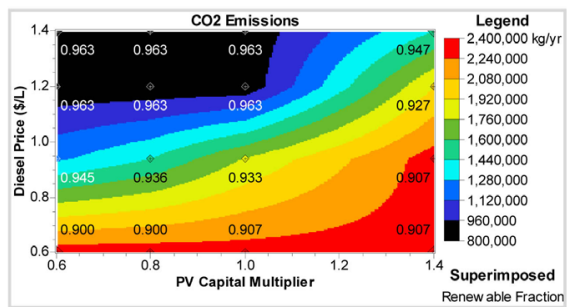

(d)

Figure 8. Shows HOMER simulation results of different systems output characteristics under given sensitivity values (Diesel Price versus PV capital multiplier (a) the optimal system type, (b) Surface plot diagram for wind energy production, (c) Surface plot diagram for renewable penetration/fraction, (d) Surface plot diagram $\mathrm{CO}_{2}$ emissions). 
by looking at the surface plot diagrams of Figure 8(c) and Figure 8(d). Here one might need to make sure the future market trend for sensitive variables. If $\mathrm{PV}$ has a tendency to get cheaper but fuel rather gets costlier in the future, the upper left orange color region in Figure 8 (c) is an ideal choice with $97 \%$ electricity generation from wind turbine with very less frequent genset operation to minimize cost as well as $\mathrm{CO}_{2}$ emission of more than $96 \%$ as indicated in Figure 8(d) compared to the "diesel generator only" case to meet the same load.

\subsection{Comparison of Hybrid Energy System with Stand-Alone Diesel Generator}

The overall lifetime expense of the Diesel generator power plant is almost equaling to the cost expended for fuel as it is shown in Figure 9. Otherwise, the initial capital cost is almost negligible compared with other costs and even with that of Hybrid Renewable Energy.

\subsection{Comparison of Hybrid Energy System with Grid Extension}

Geladin district is $682 \mathrm{~km}$ away from the national electricity grid owned by EEPCo and as it is seen in the detailed cost estimation of grid extension option, the initial capital for the calculated $132 \mathrm{kV}$ transmission line including all accessories (pole, overhead line, transformers, circuit breakers etc.) is 223,649,924USD and this value is much higher than (14 times) the initial capital cost of the proposed hybrid system as shown in Table 6.

\section{Conclusions}

The result of this work reveals a system comprising Wind turbine/PV/Genset with a rechargeable battery bank architecture is the most economical option to the geographical site in question compared to other alternatives such as grid extension, diesel generator, PV and wind power systems in terms of TNPC and the cost of generation. The base power for the site comes from wind but power from the solar module and backup generator bridges the supply gap if any. For physical implementation of the system, there needs energy dispatch controller which determines when the battery bank charges and discharges and what level of limit for depth of charge (DOC) and state of charge (SOC) to maintain, when the diesel generator should start, which load to prioritize, what to do when load demand and supply mismatch etc., thus control the power balance of the system dynamics. Such device is found in the model architecture of Figure 5 by the name converter but in fact it is the brain of the system which consists of power electronics and other devices such as rectifier, inverter, high-frequency switching dc-dc boost converter, AC and DC filters, Micro-controller and power transformer. The whole system can be best controlled by a closed loop feedback control simply by programming ( $\mathrm{C}$ code) a Texas Instrument micro-controller appropriate model. The control system part is not the scope of this study and is therefore recommended for future studies to more closely understand and solve the system dynamic behavior in such large-scale RES systems design. 


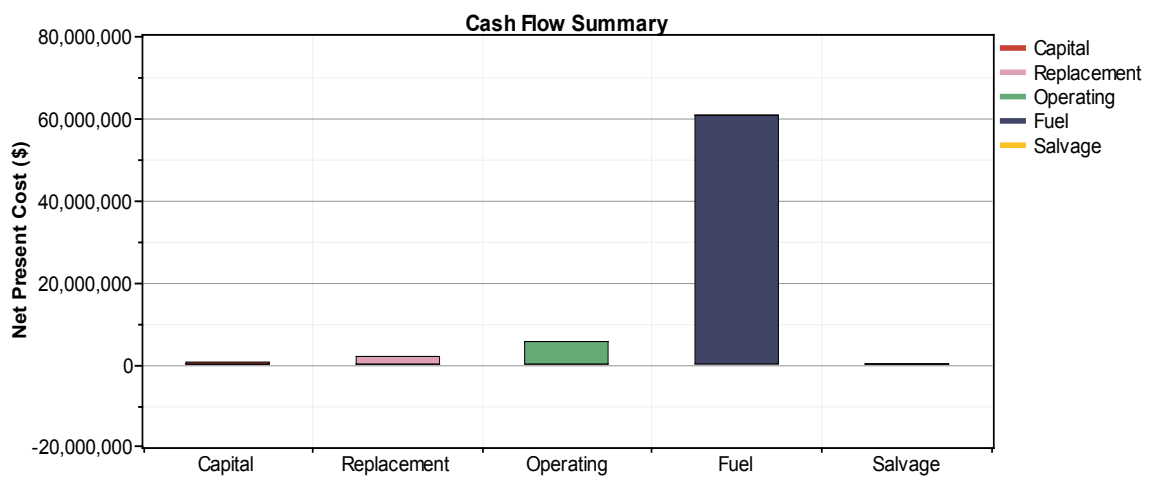

Figure 9. Distribution of life time cost (NPC) of the DGO system.

Table 6. Grid extension comparison with the Stand-alone diesel systems and hybrid system.

\begin{tabular}{ccccc}
\hline $\begin{array}{c}\text { Type of Power } \\
\text { System }\end{array}$ & $\begin{array}{c}\text { Initial Capital } \\
\text { (USD) }\end{array}$ & $\begin{array}{c}\text { NPC } \\
\text { (USD) }\end{array}$ & $\begin{array}{c}\text { COE } \\
\text { (USD/KWh) }\end{array}$ & $\begin{array}{c}\text { Break-even } \\
\text { Distance (km) }\end{array}$ \\
\hline PV/Wind T/Gen/Bat & $15,620,248$ & $25,186,892$ & 0.11 & 48.9 \\
D. Generator & 698,477 & $69,342,016$ & 0.33 & 155 \\
Grid Extension & $223,649,924$ & $228,122,223$ & 0.742 & - \\
\hline
\end{tabular}

Since the site is near to the Gulf of Aden, it has the benefit of a huge wind energy potential availability and therefore $92 \%$ of the power comes from wind turbine for this specific design. One of the important contributions of this study is a lower COE compared to other similar studies in the field due to the characteristic nature of large-scale hybrid system and very high wind power penetration. Wind power penetration close to $100 \%$ is advisable if the average wind speed is higher than $7 \mathrm{~m} / \mathrm{s}$.

The challenge of excess energy production affects the overall system efficiency and therefore, a further study must be done to effectively divert the excess energy production during very high wind speed hours and seasons to other electric loads or energy storages such as hot water and/or pumped storage so that the overall system could be better efficient and balanced. This is a win-win situation for both utility and customer side of economics though the technology for the best system control strategy (modular control hardware and driver software which is represented in this study as "converter") might slightly seem to increase the RES initial investment.

The diesel fuel consumption of the designed hybrid system is only $12 \%$ compared to diesel generator stand-alone system. This is very important to this site not only in reducing fuel costs but also in minimizing the inconveniency of transportation of fuel to the site and its capability in critical reduction of $\mathrm{CO}_{2}$ emission by $88.93 \%$. Therefore, this study concludes the site in question and other similar climatic areas is more appropriate and recommended if electrified with wind/PV/diesel/battery hybrid system to address the local customers' energy demand in a cheap and eco-friendly way, thus improving every aspect of people's life. 


\section{Conflicts of Interest}

The authors declare no conflicts of interest regarding the publication of this paper.

\section{References}

[1] The International Bank for Reconstruction and Development (2008) The Little Data Book on Africa. World Bank, Washington DC.

[2] CIA. The World Factbook. https://www.cia.gov https://www.cia.gov/library/publications/the-world-factbook/geos/et.html

[3] USAID. Power Africa in Ethiopia. USAID Website. https://www.usaid.gov

[4] Alliance for Rural Electrification. Hybrid Power Systems Based on Renewable Energies; Suitable and Cost Competitive Solution for Rural Electrification.

[5] Nfaha, E.M. and Ngundam, J.M. (2008) Simulation of Off-Grid Generation Options for Remote Villages in Cameroon. Renewable Energy, 33, 1064-1072. https://doi.org/10.1016/j.renene.2007.05.045

[6] Unicef. http://www.unicef.org/ethiopia

[7] Solar and Wind Energy Resource Assesment (SWERA). SWERA Website. http://en.openei.org/apps/SWERA

[8] UN Data (2007). http://data.un.org/CountryProfile.aspx?crName=Ethiopia

[9] The World Bank International Development Association (2015) Implementation Completion and Results Report Second for Ethiopian Electricity Access (Rural) Expansion Project. Energy and Extractives Global Practice Country Department AFCE3. Report No. ICR3135.

[10] Markvart, T. (1996) Sizing of Hybrid PV-Wind Energy Systems. Solar Energy, 59, 277-281. https://doi.org/10.1016/S0038-092X(96)00106-5

[11] Elhadidy, M.A. and Shaahid, S.M. (2000) Parametric Study of Hybrid (Wind + Solar + Diesel) Power Generating Systems. Journal of Renewable Energy, 21, 129-138. https://doi.org/10.1016/S0960-1481(00)00040-9

[12] Central Statistical Agency. http://www.csa.gov.et

[13] Tesema, S. and Bekele, G. (2014) Resource Assessment and Optimization Study of Efficient Type Hybrid Power System for Electrification of Rural District in Ethiopia. International Journal of Energy and Power Engineering, 3, 331-340. https://doi.org/10.11648/j.ijepe.20140306.16

[14] Lakew, S.T. (2015) Renewable Energy System Modelling and Techno-Economic Analysis. LAP Lambert Publishing, Düsseldorf.

[15] Veeran, P.K. and Kumar, S. (1993) Analysis of Monthly Average Daily Global Radiation and Monthly Average Sunshine Duration at Two tropical Locations. Renewable Energy, 3, 935-939. https://doi.org/10.1016/0960-1481(93)90054-K

[16] Drake, F. and Mulugeta, Y. (1996) Assessment of Solar and Wind Energy in Ethiopia. I. Solar Energy. Solar Energy, 57, 205-217. https://doi.org/10.1016/S0038-092X(96)00094-1

[17] Mulugeta, Y. and Drake, F. (1996) Assessment of Solar and Wind Energy Resources in Ethiopia: II. Wind Energy. Solar Energy, 57, 323-334. https://doi.org/10.1016/S0038-092X(96)00074-6

[18] Woldeghiorgis, W. (1988) Wind Energy Survey in Ethiopia. Journal of Solar \& Wind Technology, 5, 341-351. 
[19] Homer V2.68 Beta, National Renewable Energy Laboratory (NREL), 617 Cole Boulevard. https://users.homerenergy.com

[20] Central Statistical Agency, "Census: Complete Report, Census 2007: Central Statistical Agency”. http://www.csa.gov.et

[21] Patel, M.R. (1999) Wind and Solar Power System. CRC Press, New York.

[22] MES (2013) Comparison of Underground and Overhead Transmission Options in Iceland (132 and 220kV). Technical Report, METSCO Energy Solution.

[23] Nehrir, M.H. and Strunz, C. (2013) A Review of Hybrid Renewable/Alternative Energy for Electric Power Generation. IEEE Transaction on Sustainable Energy, 2, 392-403.

[24] Givler, T. and Lilienthal, P. (2005) Using HOMER Software, NREL's Micro-Power Optimization Model, to Explore the Role of Gen-Sets in Small Solar Power Systems; Case Study: Sri Lanka Technical Report. National Renewable Energy Laboratory. 